\title{
Geographical and Genetic Divergence Among Papaya ringspot virus Populations Within Hainan Province, China
}

\author{
Hui Zhao, Rui Zong Jia, Yu-Liang Zhang, Yun Judy Zhu, Hui-Cai Zeng, Hua Kong, Heather McCafferty, \\ An-Ping Guo, and Ming Peng
}

First author: College of Agriculture, Hainan University, Haikou, Hainan, China 570228; first, second, third, fourth, fifth, sixth, eighth, and ninth authors: Key Laboratory of Biology and Genetic Resources of Tropical Crops, Ministry of Agriculture, P.R. China, and Institute of Tropical Bioscience and Biotechnology, Chinese Academy of Tropical Agriculture Sciences, Haikou, Hainan, China 571101; and second, fourth, and seventh authors: Hawaii Agriculture Research Center, Waipahu 96797.

Accepted for publication 1 April 2016.

\begin{abstract}
Zhao, H., Jia, R. Z., Zhang, Y.-L., Zhu, Y. J., Zeng, H.-C., Kong, H., McCafferty, H., Guo, A.-P., and Peng, M. 2016. Geographical and genetic divergence among Papaya ringspot virus populations within Hainan Province, China. Phytopathology 106:937-944.

Papaya ringspot virus (PRSV) severely affects the global papaya industry. Transgenic papaya has been proven to have effective resistance to PRSV isolates from Hawaii, Thailand, Taiwan, and other countries.

papaya planting areas across five cities (Wen Chang, $n=13$; Cheng Mai, $n=14$; Chang Jiang, $n=11$; Le Dong, $n=25$; and San Ya, $n=13$ ) within Hainan Province, were investigated. Results revealed three genetic diversity groups (Hainan I, II, and III) that correlated with geographical distribution. Frequent mutations among PRSV isolates from Hainan were also observed. The high genetic divergence in PRSV isolates from Hainan is likely to be the cause of the failure of genetically modified papaya that targets sequence-specific virus.
\end{abstract} However, those transgenic cultivars failed to show resistance to Hainan Island isolates. Some 76 PRSV samples, representative of all traditional
Additional keywords: coat protein.
Papaya ringspot virus (PRSV; genus Potyvirus, family Potyviridae) is the most important virus that threatens papaya and cucurbit plants in tropical and subtropical areas. Papaya exhibits typical viral disease symptoms (leaf yellowing, distortion, and severe mosaic) and also the classic "ringspot" on the fruit. The viruses are transmitted by aphids quickly and easily between plants. Two major types (PRSV-P and PRSV-W) were hard to identify by a serological method but were distinguished by host specificity (Purcifull and Hiebert 1979). PRSV-P mainly infects papaya and several members of the melon family (Cucurbitaceae), while PRSV-W does not infect papaya but infects cucurbits such as watermelon, cucumber, and squash (Webb and Scott 1965). The full-length genome of PRSV contained P1 protein (protease), helper-component proteinase (HCPro), $\mathrm{P} 3$ protein (6K1 protein), CI protein (6K2 protein), nuclear inclusion a protein (NIa), nuclear inclusion b protein (NIb), and coat protein (CP) (Yeh et al. 1992).

From a global perspective, the most effective method of prevention and control of PRSV are to cultivate virus-resistant transgenic varieties. The world's first commercialized transgenic papaya, containing the PRSV CP gene, was introduced to Hawaii in 1998, where PRSV had almost wiped out the entire papaya industry (Ferreira et al. 2002). Transformation of the Hawaii PRSV HA 5-1 $C P$ gene into papaya impaired virus replication and movement in the original transgenic papaya 'SunUp' and in its commercial cultivar, 'UH Rainbow', a high level of resistance to Hawaii PRSV

Corresponding authors: A.-P. Guo; E-mail address: gap211@126.com; and M. Peng; E-mail address: mmpeng_2000@yahoo.com

H. Zhao and R. Z. Jia contributed equally to this work.

GenBank submission: sequence accession numbers KF002591 to KF002709.

http://dx.doi.org/10.1094/PHYTO-05-15-0111-R

(c) 2016 The American Phytopathological Society isolates was exhibited. However, the transgenic papaya has varying defense against PRSV isolates from other geographical regions. With isolates from the Bahamas, Florida, and Mexico, symptoms are delayed and reduced; whereas, with isolates from Brazil or Thailand, symptoms are also delayed but resistance eventually fails (Tennant et al. 1994). The CP hemizygous line 'Rainbow' is also susceptible to Taiwan PRSV isolates (Kung et al. 2009). Thus, resistance is affected by divergence within the $C P$ gene. Double resistance to both PRSV and Papaya leaf-distortion mosaic virus (PLDMV) was achieved by transforming with a construct containing the truncated CP coding region of the PLDMV PTW-WF Taiwan isolate and the truncated $\mathrm{CP}$ coding region with the complete 3' untranslated region of PRSV YK Taiwan isolates. The double mutation showed high levels of resistance to heterologous PRSV isolates originating from Hawaii, Thailand, and Mexico (Kung et al. 2009). Researchers at Guangdong also developed a transgenic papaya containing PRSV NIb replicase protein fragments that conferred resistance to local isolates (Rao et al. 2012). Unfortunately, neither of the transformed lines mentioned have effective or permanent resistance to Hainan PRSV isolates (personal communication with Hainan papaya grower, also confirmed in lab experiments; data not presented).

Hainan is the most important papaya-producing region in China, and papaya ringspot disease remains a serious threat to papaya production in Hainan. For example, in Le Dong city, the papaya planting area was reduced from 6,700 ha in 2010 to 2,700 ha in 2011, then further reduced to 1,300 ha in 2012 due to the disease (Qian 2012). Our previous studies reported the first full-length Hainan PRSV genome (PRSV-HN, EF183499) (Lu et al. 2008) and, subsequently, a second full-length PRSV genome (PRSV-HN2, HQ424465) (Tuo 2011). However, those isolates were randomly collected from the experimental station of the Chinese Academy of Tropical Agriculture Sciences. Thus, limited information is available to predict PRSV diversity in Hainan and their distribution 
across the island. Our hypothesis is that the broad divergence of PRSV in Hainan caused the failure of resistance for transformed papaya from Hawaii, Taiwan, and Guangdong. Thus, this work focused on understanding the distribution and genetic diversity of PRSV that is important for management of the disease in Hainan.

\section{MATERIALS AND METHODS}

Samples and locations. Fresh leaf samples of papaya (Carica papaya L.) were collected from traditional papaya-planting cities Wen Chang, Cheng Mai, Chang Jiang, Le Dong, and San Ya in Hainan Province in China from March to June 2010 (Fig. 1). No specific permissions were required for these locations or activities for papaya leaf collection. More than 10 samples from each city were randomly picked from the fields of papaya farms and stored on ice for no more than $12 \mathrm{~h}$ prior to being frozen in liquid nitrogen and subsequently stored at $-80^{\circ} \mathrm{C}$.

Viral RNA extraction and cDNA cloning and sequencing. Total plant or viral RNA were extracted from the papaya leaves following the method of $\mathrm{Lu}$ et al. (2008). The first-strand cDNA was synthesized using moloney murine Leukemia virus reverse transcriptase (M-MLV RT) (TransGen) following the manufacturer's manual, with a combination of random primers and oligo $\mathrm{dT}(15)$ primers. The primers used to detect the PRSV $C P$ gene (forward TCATCAGTCCAAGAATGAAGCTGTGG and reverse GGCCACCCACACTGTATGGAG), HC-Pro gene (forward GCRGCTCTKGCAACCATAATC, reverse TRCGCAAAGCRATR CACTCACG), and NIb gene (forward GATTTCAATAATTGGTTC TACAG and reverse TTCATGRTAYACCAGTARCTCAGG) were designed by Primer Premier (v5; Premier Biosoft International). The polymerase chain reaction (PCR) mixture contained $1 \mu \mathrm{l}$ of cDNA, $0.5 \mu \mathrm{l}$ of each primer $(10 \mu \mathrm{M}), 2 \mu \mathrm{l}$ of $10 \times$ PCR buffer, $1 \mu \mathrm{l}$ of dNTP, $0.25 \mathrm{U}$ of Taq DNA polymerase (Takara), and nuclease-free water to a final volume of $20 \mu \mathrm{l}$. The amplification consisted of 35 cycles at $94^{\circ} \mathrm{C}$ (30 s), $50^{\circ} \mathrm{C}(1 \mathrm{~min})$, and $72^{\circ} \mathrm{C}(1 \mathrm{~min})$; the initial cycle incorporated a melting step of $94^{\circ} \mathrm{C}$ for $3 \mathrm{~min}$ and the final cycle a synthesis step of $72^{\circ} \mathrm{C}$ for $10 \mathrm{~min}$. PCR products were subjected to electrophoresis on a $1.5 \%$ agarose gel, and visualized with ethidium bromide staining.

Sequencing and sequence analysis. The PCR products were purified using the TianGen Gel Extraction Kit (TianGen), and cloned into the pMD19-T vector (Takara) following the manufacturer's protocol, then transformed into Escherichia coli DH5 $\alpha-$ competent cells. Three positive colonies from each transformation were selected and sequenced (Abi 3130xl Genetic Analyzer; Hitachi). Identical sequences from three colonies were considered to be the final sequence.

Sequences were assembled and preanalyzed with BioEdit (v7) (Hall 1999). PRSV CP, NIb, and HC-Pro gene fragments were aligned with ClustalW (Larkin et al. 2007). Phylogenetic analysis was conducted in MEGA5 (Tamura et al. 2011). All phylogenetic trees were inferred by using the neighbor-joining (NJ) method (Saitou and Nei 1987). The percentage of replicate trees with the bootstrap test $(1,000$ replicates) was shown next to the branches and a value less than 50 indicated a higher possibility of collapse (Felsenstein 1985). Researchers found that a concatenation of multigenes has shown higher resolution as well as integration of more information (Teichmann and Mitchison 1999). In our work, we also generated a concatenation tree ( $\mathrm{CP}, \mathrm{NIb}$, and $\mathrm{HC}$-Pro) to interpret the biodiversity of PRSV isolated in Hainan.

Statistical analysis. All identified PRSV isolates from three subgroups (I, II, and III) were indexed as 1, 2, and 3, respectively, in terms of diversity subgroups, while the cities where the samples was collected-Wen Chang, Cheng Mai, Chang Jiang, Le Dong, and San Ya-were indexed 1, 2, 3, 4, and 5, respectively, in terms of geographical distribution. The correlation of PRSV diversity (subgroups) and their geographical distribution were analyzed by using the correspondence analysis procedure (CORRESP) in SAS (v8; SAS Inc.).

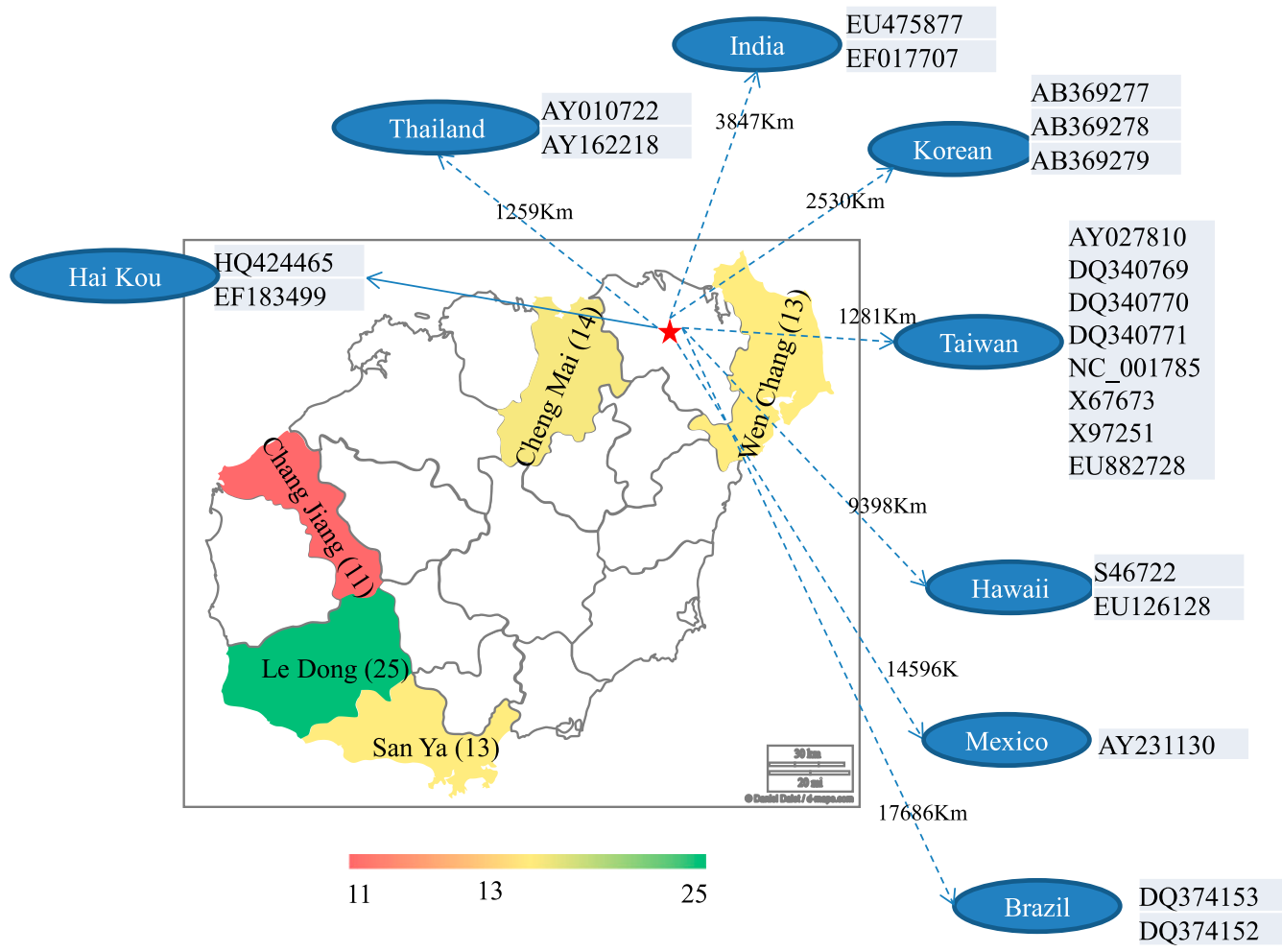

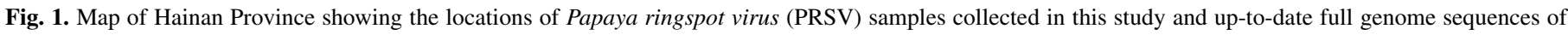

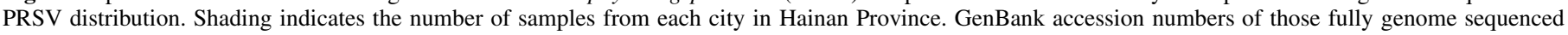

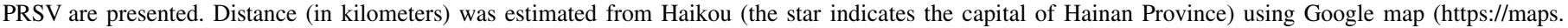
google.com). 


\section{RESULTS}

Sensitive detection of PRSV by PCR. In total, 76 samples from four cities across Hainan Island were collected and listed in Table 1, including 61 samples with symptoms, 12 symptomless, and 3 samples not determined by visual check but later confirmed as positive with PCR testing. In Cheng Mai, 8 of 14 samples with typical PRSV symptoms were also confirmed as positive by PCR testing of the three genes ( $C P, N I b$, and $H C$-Pro). Additionally, F8d, F9d, and F10d were collected from one tree due to slightly different visual symptoms (data not show), and all those samples were virus positive as confirmed by PCR amplification. Of 11 samples from Chang Jiang with symptoms, 10 were confirmed by PCR results, except F15d that had visual symptoms but was not positive with any of the three tests. Of 13 samples from Wen Chang, 10 had symptoms and were confirmed by PCR. Of 25 samples from Le Dong, 21 had symptoms and also had a positive PCR test, except F60d and F63d, which were confirmed as PLDMV (data not shown). Of 13 samples from San Ya city, 10 were positive in both visual symptoms and PCR test. The PCR method has proved to be an effective method to detect the virus in the early stage of PRSV infection. Some symptomless samples showed positive results. PCR results were consistent with visual symptom results. Without typical ringspot in papaya fruit, it is hard to distinguish between PRSV and PLDMV but the viruses could be separated using PCR.

Single-gene trees reveal divergence of PRSV. Phylogenetic analysis of $C P$ genes revealed three subgroups: $\mathrm{CP} 1, \mathrm{CP} 2$, and CP3 (Fig. 2A). In all, 13 isolates (24\%) categorized as CP1 were clustered with Taiwan isolates (X97251 and AY027810) and Korea isolate (AB369277). Among the CP1 subgroups, 2 isolates were from Chang Jiang and 11 isolates from Le Dong. In total, 11 isolates (21\%) were categorized as CP2 and clustered with previously reported Hainan isolates (EF183499). Among those, four isolates were from Wen Chang city, four isolates were from Chang Jiang, and two isolates were from Le Dong. In all, 29 isolates (55\%) were in the CP3 subgroup, which was dominant and comprised isolates from all sampled cities.

Sequence analysis of $N I b$ genes (33 isolates) also divided the isolates into three subgroups: NIb1, NIb2, and NIb3 (Fig. 2B). Eight samples (24\%; two from Cheng Mai, one from Le Dong, and five from San Ya) were clustered to the NIb1 subgroup and not clustered with any reference isolates; all of their $C P$ genes were in the CP3 subgroup. The NIb2 subgroup contained two reference isolates (EF183499 and HQ424465) whose CP sequences were categorized as CP2 and CP3 subgroups, respectively. Except for EF183499, all other isolates in the NIb2 subgroup had $C P$ genes belonging to the CP3 subgroup. Five isolates (15\%) were grouped into NIb2: one from Wen Chang and four from Cheng Mai. The rest of the isolates were grouped in the NIb3 subgroup (61\%) and also not clustered with any reference sequence. Of these, six isolates were from Chang Jiang, six from Wen Chang, and eight from Le Dong.

Sequence analysis of $H C$-Pro genes also divided the isolates into three subgroups: HC-Pro1, HC-Pro2, and HC-Pro3 (Fig. 2C). The HC-Pro1 subgroup (29\%) contained seven isolates from Chang Jiang and three isolates from Le Dong and was not clustered with any reference isolate. The HC-Pro2 subgroup (21\%) contained three isolates from Cheng Mai and four isolates from Wen Chang. HC-Pro2 subgroup also contained two reference sequences (EF183499 and HQ424465) whose CP sequences were categorized in $\mathrm{CP} 2$ and $\mathrm{CP} 3$, respectively. HC-Pro3 subgroup contained 17 isolates (50\%): 1 from Chang Jiang, 1 from Wen Chang, 3 from Le Dong, 4 from Cheng Mai, and 8 from San Ya. The HC-Pro3 subgroup was not clustered with any reference isolates.

Isolates in the $\mathrm{CP} 1$ subgroup had their $C P$ genes close to Taiwan and Korea isolates whereas their NIb genes (NIb3 subgroup) and $\mathrm{HC}$-Pro genes (HC-Prol subgroup) had less similarity with those Taiwan and Korea isolates. For isolates in the CP2 subgroup, their $C P$ gene sequences were close to Hainan reference isolates
(EF183499), whereas their NIb gene sequences (NIb3 subgroup) had less similarity with reference isolates and their $H C$-Pro genes were divided into HC-Pro1 and HC-Pro2 subgroups. Their HC-Pro1 was not close to any reference isolates and the HC-Pro2 was close to two Hainan reference isolates. Isolates in the CP3 subgroup had $C P$ gene sequences clustered with another Hainan reference (HQ424465), whereas their NIb gene sequences were divided into

TABLE 1. List of papaya leaf samples collected across Hainan Island

\begin{tabular}{|c|c|c|c|c|c|c|}
\hline \multirow[b]{2}{*}{ Sample ${ }^{\mathrm{x}}$} & \multirow[b]{2}{*}{ Location $^{\mathrm{y}}$} & \multirow[b]{2}{*}{ Symptom } & \multicolumn{4}{|c|}{ RT-PCR verification ${ }^{\mathrm{w}}$} \\
\hline & & & $\mathrm{CP}$ & & $\mathrm{NIb}$ & HC-Pro \\
\hline$\overline{\text { F1d }}$ & $\mathrm{CM}$ & Positive & (+) KF002658 & $(+)$ & KF002591 & (+) KF002624 \\
\hline $\mathrm{F} 2 \mathrm{~d}$ & $\mathrm{CM}$ & Positive & (+) KF002659 & $(-)$ & & (-) \\
\hline $\mathrm{F} 3 \mathrm{~d}$ & $\mathrm{CM}$ & Positive & (+) KF002660 & $(-)$ & & (+) KF002625 \\
\hline F4d & $\mathrm{CM}$ & Negative & $(-)$ & $(-)$ & & $(-)$ \\
\hline F5d & $\mathrm{CM}$ & Negative & $(-)$ & $(-)$ & & $(-)$ \\
\hline F6d & $\mathrm{CM}$ & Negative & $(-)$ & $(-)$ & & $(-)$ \\
\hline F7d & $\mathrm{CM}$ & Negative & $(-)$ & $(-)$ & & $(-)$ \\
\hline F8d a & $\mathrm{CM}$ & Positive & (+) KF002661 & $(+)$ & KF002592 & (+) KF002626 \\
\hline F9d a & $\mathrm{CM}$ & Positive & (+) KF002662 & $(+)$ & KF002593 & (+) KF002627 \\
\hline F10d a & $\mathrm{CM}$ & Positive & (+) KF002663 & $(+)$ & KF002594 & (+) KF002628 \\
\hline F11d & $\mathrm{CM}$ & Negative & $(-)$ & $(-)$ & & $(-)$ \\
\hline F12d b & $\mathrm{CM}$ & Positive & (+) KF002664 & $(+)$ & KF002595 & (+) KF002629 \\
\hline F13d b & $\mathrm{CM}$ & Negative & $(-)$ & $(-)$ & & $(-)$ \\
\hline F14d & $\mathrm{CM}$ & Positive & (+) KF002665 & $(+)$ & KF002596 & (+) KF002630 \\
\hline $\mathrm{F} 15 \mathrm{~d}$ & $\mathrm{CJ}$ & Positive & $(-)$ & $(-)$ & & $(-)$ \\
\hline F16d & $\mathrm{CJ}$ & Positive & (+) KF002666 & $(-)$ & & (+) KF002631 \\
\hline F17d & $\mathrm{CJ}$ & Positive & (+) KF002667 & $(+)$ & KF002597 & (+) KF002632 \\
\hline F18d & $\mathrm{CJ}$ & Positive & (+) KF002668 & $(-)$ & & (-) \\
\hline F19d & CJ & Positive & (+) KF002669 & $(+)$ & KF002598 & (+) KF002633 \\
\hline $\mathrm{F} 20 \mathrm{~d}$ & $\mathrm{CJ}$ & Positive & (+) KF002670 & $(-)$ & & (+) KF002634 \\
\hline F21d & $\mathrm{CJ}$ & Positive & (+) KF002671 & $(+)$ & KF002599 & (+) KF002635 \\
\hline $\mathrm{F} 22 \mathrm{~d}$ & $\mathrm{CJ}$ & Positive & (+) KF002672 & $(+)$ & KF002600 & (+) KF002636 \\
\hline $\mathrm{F} 23 \mathrm{~d}$ & $\mathrm{CJ}$ & Positive & $(-)$ & $(+) 1$ & KF002601 & (+) KF002637 \\
\hline $\mathrm{F} 24 \mathrm{~d}$ & CJ & Negative & $(-)$ & $(-)$ & & $(-)$ \\
\hline $\mathrm{F} 25 \mathrm{~d}$ & $\mathrm{CJ}$ & Positive & $(-)$ & $(+)$ & KF002602 & (+) KF002638 \\
\hline $\mathrm{F} 26 \mathrm{~d}$ & WC & Positive & (+) KF002673 & $(+)$ & KF002603 & (+) KF002639 \\
\hline $\mathrm{F} 27 \mathrm{~d}$ & WC & Positive & $(-)$ & $(+)$ & KF002604 & (+) KF002640 \\
\hline $\mathrm{F} 28 \mathrm{~d}$ & WC & Negative & $(-)$ & $(-)$ & & $(-)$ \\
\hline $\mathrm{F} 29 \mathrm{~d}$ & WC & Positive & (+) KF002674 & $(+)$ & KF002605 & $(-)$ \\
\hline F30d & WC & Positive & (+) KF002675 & $(-)$ & & (+) KF002641 \\
\hline F31d & WC & Positive & (+) KF002676 & $(-)$ & & (+) KF002642 \\
\hline $\mathrm{F} 32 \mathrm{~d}$ & WC & Negative & $(-)$ & $(-)$ & & $(-)$ \\
\hline $\mathrm{F} 33 \mathrm{~d}$ & WC & Positive & (+) KF002677 & $(+)$ & KF002606 & $(-)$ \\
\hline F34d & WC & Positive & $(-)$ & $(+)$ & KF002607 & $(-)$ \\
\hline $\mathrm{F} 35 \mathrm{~d}$ & WC & Negative & $(-)$ & $(-)$ & & $(-)$ \\
\hline F36d & WC & Positive & (+) KF002678 & $(-)$ & & (+) KF002643 \\
\hline F37d & WC & Positive & (+) KF002679 & $(+)$ & KF002608 & $(-)$ \\
\hline F38d & WC & Positive & (+) KF002680 & $(+)$ & KF002609 & $(-)$ \\
\hline F39d & LD & Positive & (+) KF002681 & $(+)$ & KF002610 & $(-)$ \\
\hline F40d & LD & Positive & (+) KF002682 & (+) 1 & KF002611 & (+) KF002644 \\
\hline F41d & LD & Positive & $(-)$ & $(-)$ & & $(-)$ \\
\hline $\mathrm{F} 42 \mathrm{~d}$ & LD & Positive & (+) KF002683 & $(+)$ & KF002612 & $(-)$ \\
\hline $\mathrm{F} 43 \mathrm{~d}$ & LD & Positive & $(-)$ & $(+)$ & KF002613 & $(-)$ \\
\hline $\mathrm{F} 44 \mathrm{~d}$ & LD & Positive & (+) KF002684 & $(+)$ & KF002614 & $(-)$ \\
\hline $\mathrm{F} 45 \mathrm{~d}$ & LD & Positive & $(-)$ & $(+)$ & KF002615 & (+) KF002645 \\
\hline $\mathrm{F} 46 \mathrm{~d}$ & LD & Positive & $(-)$ & (+) 1 & KF002616 & $(-)$ \\
\hline F47d & LD & Positive & (+) KF002685 & $(-)$ & & $(-)$ \\
\hline $\mathrm{F} 48 \mathrm{~d}$ & LD & Positive & (+) KF002686 & $(+)$ & KF002617 & $(-)$ \\
\hline $\mathrm{F} 49 \mathrm{~d}$ & LD & Positive & (+) KF002687 & $(-)$ & & (+) KF002646 \\
\hline F50d & LD & Positive & (+) KF002688 & $(-)$ & & $(-)$ \\
\hline F51d & LD & Positive & (+) KF002689 & $(-)$ & & $(-)$ \\
\hline $\mathrm{F} 52 \mathrm{~d}^{\mathrm{z}}$ & LD & ND & (+) KF002690 & $(-)$ & & $(-)$ \\
\hline $\mathrm{F} 53 \mathrm{~d}^{\mathrm{z}}$ & LD & ND & (+) KF002691 & $(-)$ & & $(-)$ \\
\hline $\mathrm{F} 54 \mathrm{~d}^{\mathrm{z}}$ & LD & ND & (+) KF002692 & $(-)$ & & $(-)$ \\
\hline F55d & LD & Positive & $(-)$ & $(-)$ & & $(-)$ \\
\hline F56d & LD & Positive & $(-)$ & $(-)$ & & $(-)$ \\
\hline F57d & LD & Positive & (+) KF002693 & $(-)$ & & (+) KF002647 \\
\hline F58d & LD & Positive & (+) KF002694 & $(+)$ & KF002618 & (+) KF002648 \\
\hline F59d & LD & Negative & $(-)$ & $(-)$ & & (-) \\
\hline F60d & LD & Positive & (+) KF002695 & $(-)$ & & $(-)$ \\
\hline F61d & LD & Positive & (+) KF002696 & $(-)$ & & (+) KF002649 \\
\hline F62d & LD & Positive & (+) KF002697 & $(-)$ & & $(-)$ \\
\hline F63d & LD & Positive & $(-)$ & $(-)$ & & $(-)$ \\
\hline F64d & SY & Positive & (+) KF002698 & $(-)$ & & (+) KF002650 \\
\hline F65d & SY & Positive & (+) KF002699 & $(+)$ & KF002619 & (+) KF002651 \\
\hline F66d & SY & Positive & (+) KF002700 & $(+)$ & KF002620 & (+) KF002652 \\
\hline F67d & SY & Positive & (+) KF002701 & $(+)$ & KF002621 & (+) KF002653 \\
\hline F68d & SY & Positive & (+) KF002702 & $(+)$ & KF002622 & (+) KF002654 \\
\hline F69d & SY & Positive & (+) KF002703 & $(-)$ & & $(-)$ \\
\hline F70d & SY & Positive & (+) KF002704 & $(-)$ & & $(-)$ \\
\hline F71d & SY & Negative & $(-)$ & $(-)$ & & $(-)$ \\
\hline F72d & SY & Positive & (+) KF002705 & $(-)$ & & $(-)$ \\
\hline F73d & SY & Positive & (+) KF002706 & $(+)$ & KF002623 & (+) KF002655 \\
\hline F74d & SY & Positive & (+) KF002707 & $(-)$ & & (+) KF002656 \\
\hline F75d & SY & Positive & (+) KF002708 & $(-)$ & & $(-)$ \\
\hline F76d & SY & Positive & (+) KF002709 & $(-)$ & & (+) KF002657 \\
\hline
\end{tabular}

${ }^{\text {w }}$ Samples positive $(+)$ or negative $(-)$ according to reverse-transcription polymerase chain reaction (RT-PCR). RT-PCR-positive samples were also sequenced and deposited in GenBank. $\mathrm{CP}=$ coat protein, $\mathrm{NIb}=$ nuclear inclusion $\mathrm{b}, \mathrm{HC}$-Pro = helper-component proteinase, and ND = not determined.

$x$ Sample names followed by the same letter ( $a$ or b) indicate samples from the same plant.

y Samples were collected in Cheng Mai (CM), Chang Jiang (CJ), Le Dong (LD), Wen Chang (WC), and San Ya (SY).

$\mathrm{z}$ Too young to visualize the symptom. 
NIb1 subgroup that has not been clustered with any reference gene and NIb2 subgroup that clustered with two Hainan references (EF183499 and HQ424465); their HC-Pro genes were clustered (HC-Pro3 subgroup) without any reference genes. In summary, $C P, N I b$, and HC-Pro genes revealed significant divergence of the PRSV in Hainan Province, and it is hard to explain the genetic diversity by using a single-gene phylogenetic analysis.

Concatenated multigene trees differentiate the PRSV groups. Concatenated $\mathrm{CP}, \mathrm{NIb}$, and $\mathrm{HC}$-Pro gene sequences from 18 representative samples and the PRSV reference genomes were used to construct the multigene tree. The concatenated multigene tree clearly presented three groups of PRSV (Hainan I, II, and II) (Fig. 3). Hainan I type PRSV was not clustered with any reference isolate, suggesting a novel group. Hainan I contained four isolates from San Ya, one isolate from Le Dong, and three isolates from Cheng Mai. Hainan II included three isolates from Cheng Mai with published reference Hainan isolate (HQ424465). Hainan III also clustered with published reference Hainan isolate (EF183499), with four isolates from Chang Jiang, one from Wen Chang, and one from Le Dong. Phylogenetic analysis revealed that Hainan I and Hainan II were closer to each other than to Hainan III. The concatenated multigene tree also set Hainan I, II, and III as a united group, differing from isolates from other parts of Southeast Asia such as Thailand, Taiwan, and Korea. The Hainan, Thailand, Taiwan, and
Korea samples were also clustered together as a super group and distinguished from the samples from India, Brazil, Mexico, and Hawaii. In our present analysis, a concatenated multigene tree can be used to separate different geographical origins.

Geographical distributions of PRSV across Hainan Province. The three Hainan-type PRSV (I, II, and III) also differed across the province (Fig. 4). Correlation analysis revealed that the novel Hainan I group viruses are more likely to be present in San Ya. Hainan II group is more likely to be present in Chen Mai, and Hainan III group was more distributed among the cities of Wen Chang and Chang Jiang.

\section{DISCUSSION}

Papaya is an economically important tropical fruit in China and in other tropical areas. PRSV causes a severe disease, which threatens the papaya industry. Efforts that include breeding for PRSV resistance and virus-free tissue culture have been carried out in Hainan for several years, with limited success. However, the inoculation results in this work confirmed that transgenic papaya from both Hawaii and Taiwan would be less resistant in Hainan (Fig. 5). Our present data show that the high divergence of Hainan PRSV and the significant phylogenetic distance are fundamental barriers to a bring-in-and-use strategy.
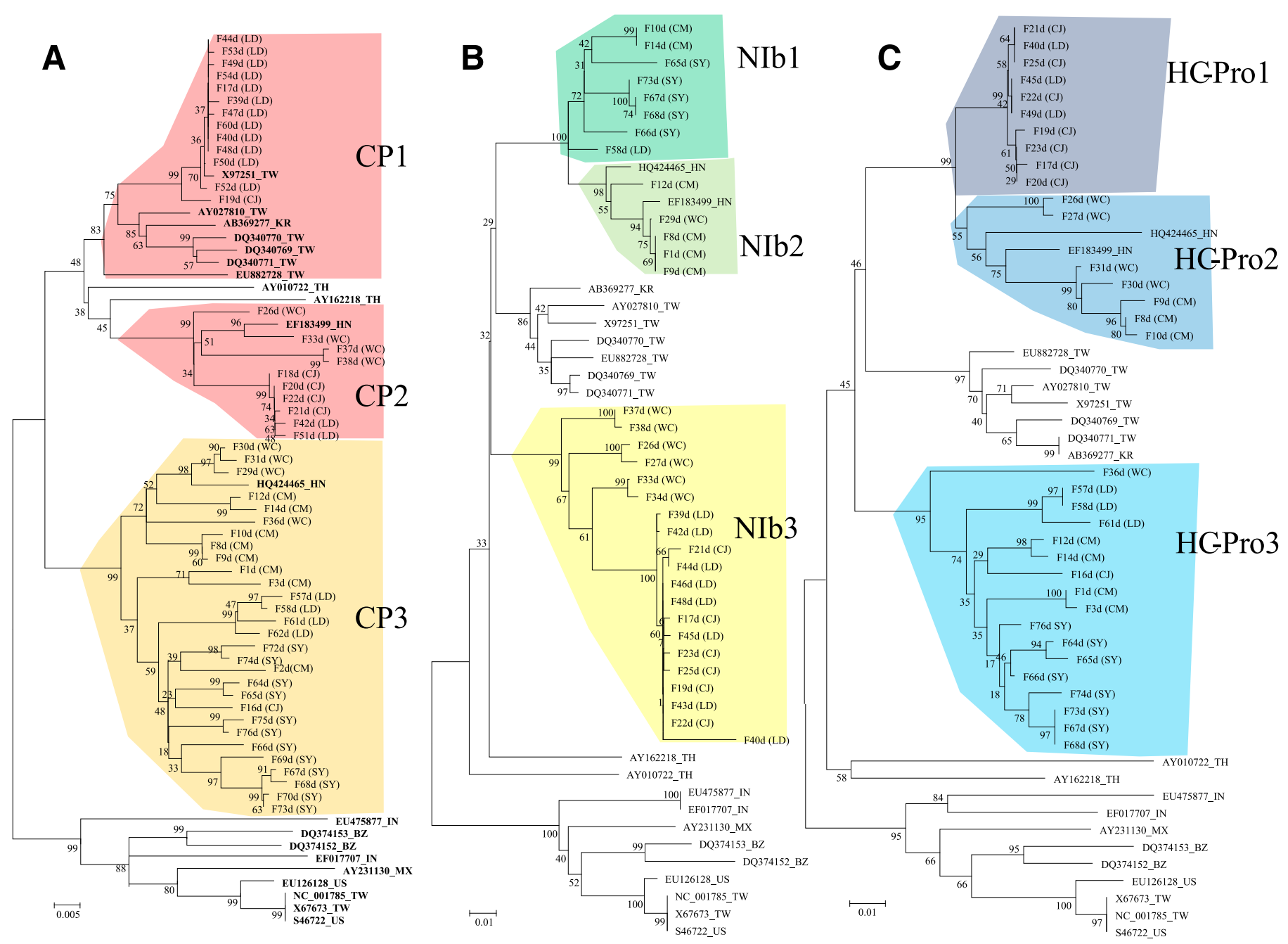

Fig. 2. Phylogenetic analysis of A, coat protein (CP); B, nuclear inclusion b protein (NIb); and $\mathbf{C}$, helper-component proteinase (HC-Pro) of Papaya ringspot virus (PRSV). The evolutionary history was inferred using the neighbor-joining method. The percentage of replicate trees in which the associated taxa clustered together in the bootstrap test (1,000 replicates) is shown next to the branches; * indicates full genome-sequenced PRSV as reference genes presented with GenBank accession number followed by the region code: $\mathrm{HN}=$ Hainan, $\mathrm{TH}=$ Thailand, $\mathrm{TW}=$ Taiwan, $\mathrm{KR}=$ Korea, $\mathrm{IN}=\mathrm{India}, \mathrm{BZ}=\mathrm{Brazil}, \mathrm{MX}=\mathrm{Mexico}$, and $\mathrm{US}=$ Hawaii. 


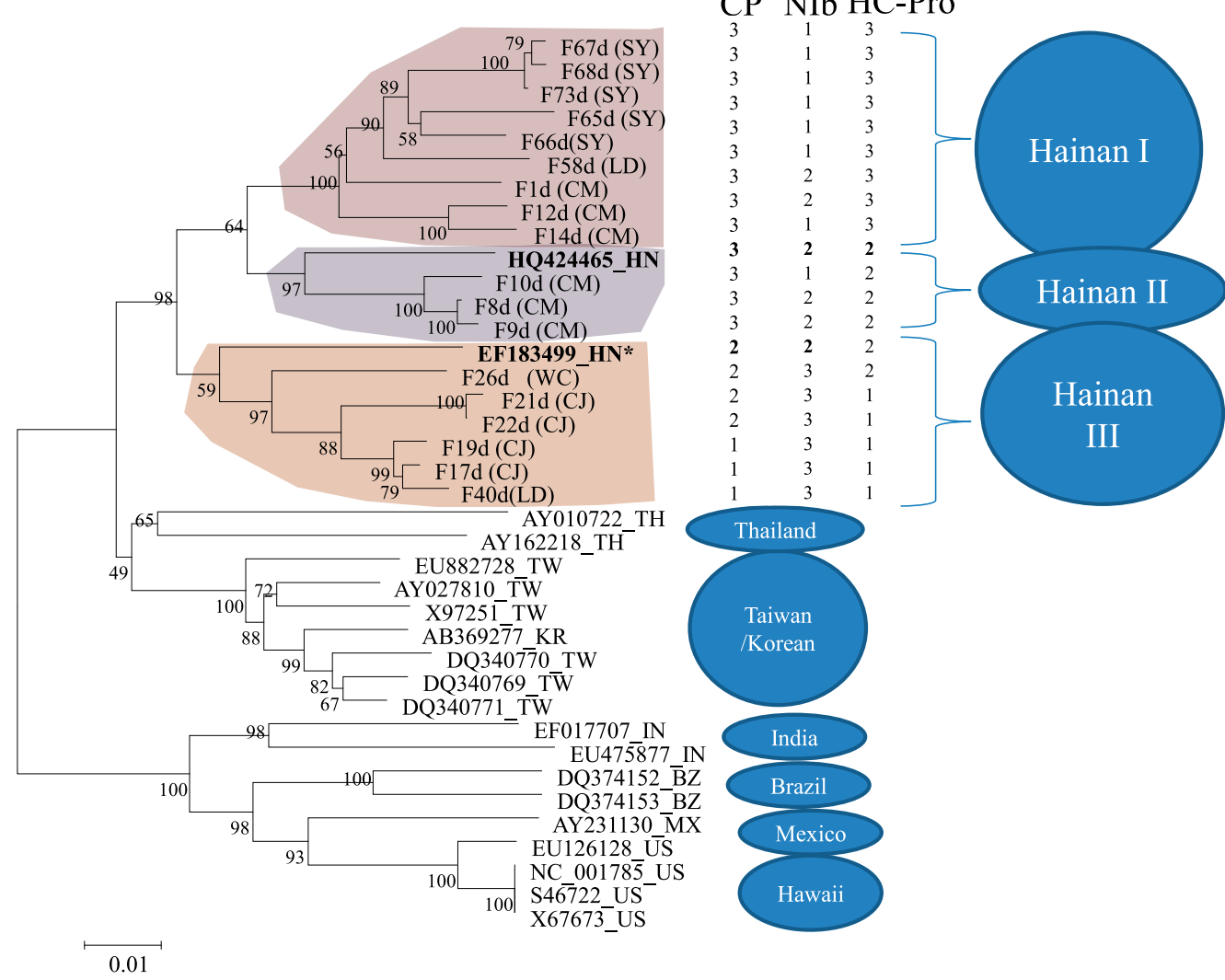

Fig. 3. Multigene concatenated trees. Neighbor-joining distance tree was calculated with 1,000 bootstrap values for those concatenated with three genes, in order: helper-component proteinase ( $\mathrm{HC}$-Pro $)$, nuclear inclusion b $(\mathrm{NIb})$, and coat protein $(\mathrm{CP})$.

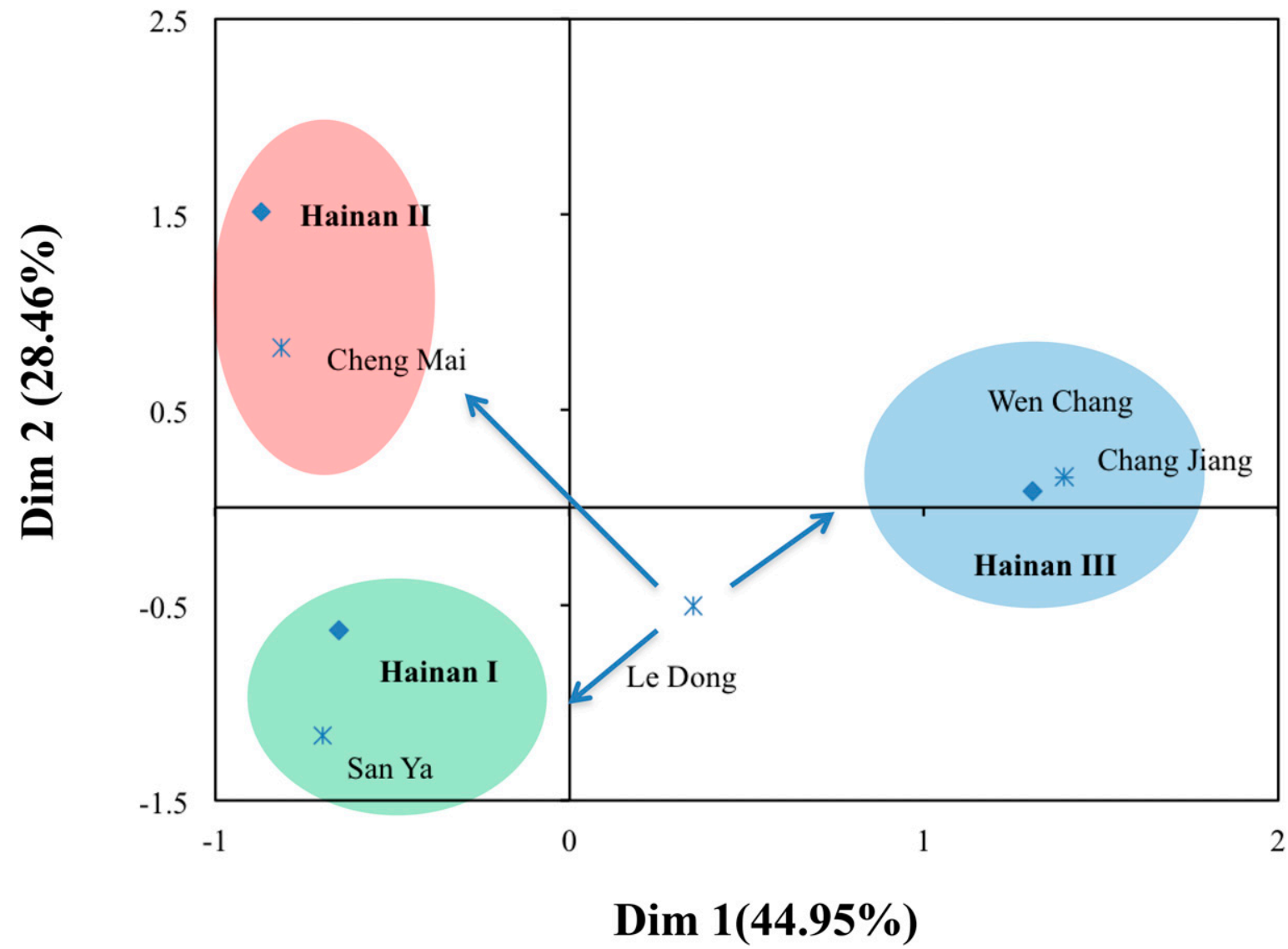

Fig. 4. Correspondence analysis of the Papaya ringspot virus phylogenetic groups and geographical distribution. Dimension 1 (Dim 1; $44.95 \%$ ) and dimension 2 (Dim $2 ; 28.46 \%$ ) show the accumulated percentage of variations. 
A

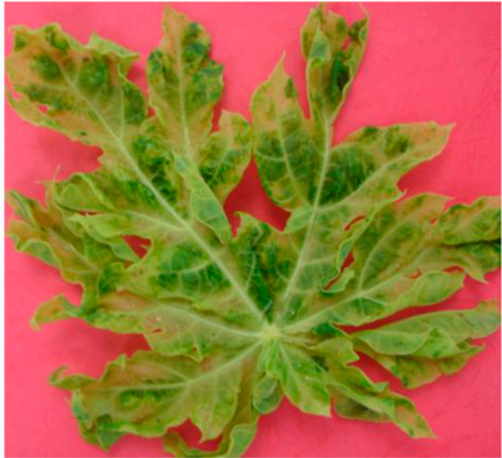

C

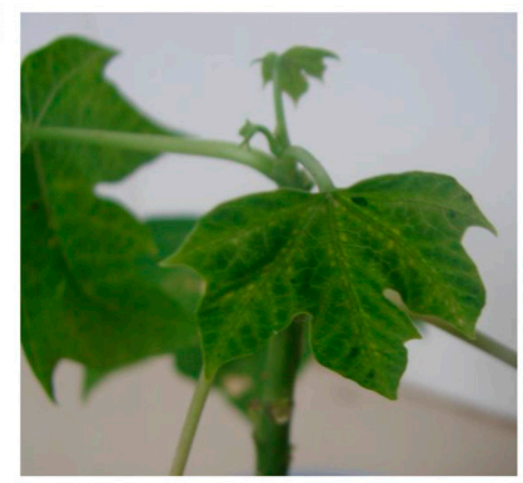

PRSV+ "Zhongbai"
B

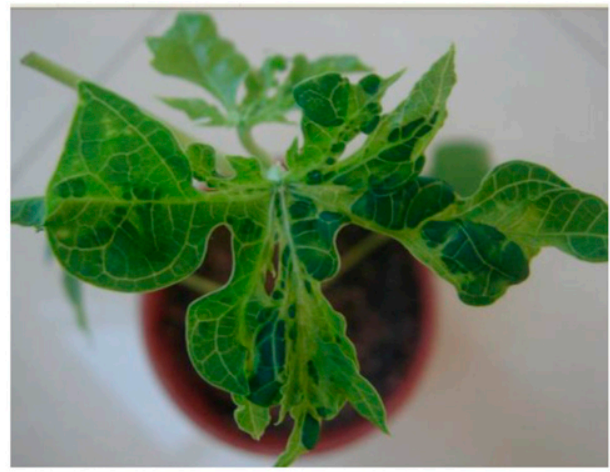

D

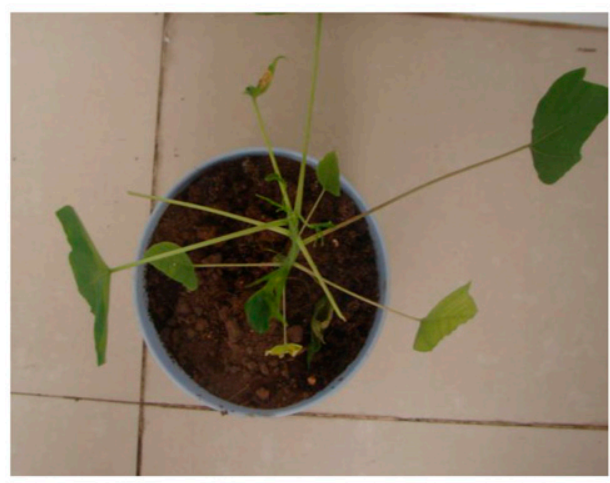

PRSV+ "UH Rainbow"

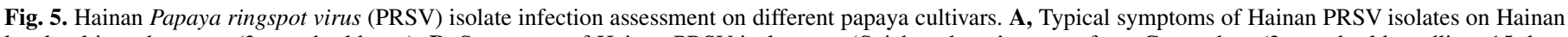

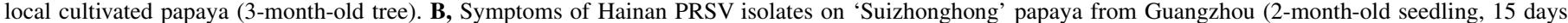

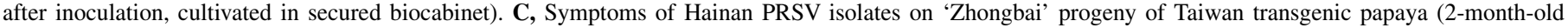

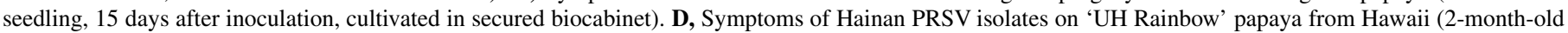
seedling, 15 days after inoculation, cultivated in secured biocabinet).

TABLE 2. Sequence alignment illustrating the mutation sites in the coat protein (CP) sequence among the Hainan Papaya ringspot virus (PRSV) isolates

\begin{tabular}{|c|c|c|}
\hline Sequence & Position & Mutation site in both DNA and amino acidz \\
\hline $\mathrm{F} 8 \mathrm{dCP}$ & 1 & $\begin{array}{l}\text { TCC-AAG-AAT-GAA-GCT-GTG-GAT-GCT-GGT-CTG-AAT-GAA-AAG-CTC- } \\
\text { AAA-GAA-AAG-GAA-AAA-CAA }\end{array}$ \\
\hline F9dCP & 1 & $\begin{array}{l}\text { TCC-AAG-AAT-GAA-GCT-GTG-GAT-GCT-GGT-CTG-AAT-GAA-AGG-CTC- } \\
\text { AAA-GAA-AAG-GAA-AAA-CAA }\end{array}$ \\
\hline \multirow[t]{2}{*}{ F10dCP } & 1 & $\begin{array}{l}\text { TCC-AAG-AAT-GAA-GCT-GTG-GAT-ACT-GGT-CTG-AAT-GAA-AAG-CTC- } \\
\text { AAA-GAA-AAG-GAA-AAA-CAA } \\
\end{array}$ \\
\hline & & $\mathrm{G}<>\mathrm{A} \mathrm{G}<>\mathrm{A}$ \\
\hline F8dCP & 1 & $-\mathrm{S}-\mathrm{K}-\mathrm{N}-\mathrm{E}-\mathrm{A}-\mathrm{V}-\mathrm{D}-\mathrm{A}-\mathrm{G}-\mathrm{L}-\mathrm{N}-\mathrm{E}-\mathrm{K}-\mathrm{L}-\mathrm{K}-\mathrm{E}-\mathrm{K}-\mathrm{E}-\mathrm{K}-\mathrm{Q}$ \\
\hline F9dCP & 1 & $-\mathrm{S}-\mathrm{K}-\mathrm{N}-\mathrm{E}-\mathrm{A}-\mathrm{V}-\mathrm{D}-\mathrm{A}-\mathrm{G}-\mathrm{L}-\mathrm{N}-\mathrm{E}-\mathrm{R}-\mathrm{L}-\mathrm{K}-\mathrm{E}-\mathrm{K}-\mathrm{E}-\mathrm{K}-\mathrm{Q}$ \\
\hline F10dCP & 1 & $-\mathrm{S}-\mathrm{K}-\mathrm{N}-\mathrm{E}-\mathrm{A}-\mathrm{V}-\mathrm{D}-\mathrm{T}-\mathrm{G}-\mathrm{L}-\mathrm{N}-\mathrm{E}-\mathrm{K}-\mathrm{L}-\mathrm{K}-\mathrm{E}-\mathrm{K}-\mathrm{E}-\mathrm{K}-\mathrm{Q}$ \\
\hline F8dCP & 661 & $\begin{array}{l}\text { TAT-GCT-TTC-GAT-TTC-TAT-GAG-GTT-AAT-TCG-AAA-ACA-CCT-GAT- } \\
\text { AGG-GCT-CGT-GAA-GCT-CAC }\end{array}$ \\
\hline F9dCP & 661 & $\begin{array}{l}\text { TAT-GCT-TTC-GAT-TTC-TAT-GAG-GTT-AAT-TCG-AAA-ACA-CCT-GAT- } \\
\text { AGG-GCT-CGT-GAA-GCT-CAC }\end{array}$ \\
\hline \multirow[t]{2}{*}{ F10dCP } & 661 & $\begin{array}{l}\text { TAT-GCT-TTC-GAT-TTC-TAT-GAG-GTT-AAT-TCG-AAA-ACA-CCT-GAT- } \\
\text { AGG-GCT-CGT-GGA-GCT-CAC }\end{array}$ \\
\hline & & $\mathrm{G}<>\mathrm{A}$ \\
\hline F8dCP & 221 & $-\mathrm{Y}-\mathrm{A}-\mathrm{F}-\mathrm{D}-\mathrm{F}-\mathrm{Y}-\mathrm{E}-\mathrm{V}-\mathrm{N}-\mathrm{S}-\mathrm{K}-\mathrm{T}-\mathrm{P}-\mathrm{D}-\mathrm{R}-\mathrm{A}-\mathrm{R}-\mathrm{E}-\mathrm{A}-\mathrm{H}$ \\
\hline F9dCP & 221 & $-\mathrm{Y}-\mathrm{A}-\mathrm{F}-\mathrm{D}-\mathrm{F}-\mathrm{Y}-\mathrm{E}-\mathrm{V}-\mathrm{N}-\mathrm{S}-\mathrm{K}-\mathrm{T}-\mathrm{P}-\mathrm{D}-\mathrm{R}-\mathrm{A}-\mathrm{R}-\mathrm{E}-\mathrm{A}-\mathrm{H}$ \\
\hline F10dCP & 221 & $-\mathrm{Y}-\mathrm{A}-\mathrm{F}-\mathrm{D}-\mathrm{F}-\mathrm{Y}-\mathrm{E}-\mathrm{V}-\mathrm{N}-\mathrm{S}-\mathrm{K}-\mathrm{T}-\mathrm{P}-\mathrm{D}-\mathrm{R}-\mathrm{A}-\mathrm{R}-\mathrm{G}-\mathrm{A}-\mathrm{H}$ \\
\hline $\mathrm{F} 8 \mathrm{dCP}$ & 841 & ATG-CAC-TCT-CTC-CTG-GGT-ATG-CGC-AAT-TAA- \\
\hline F9dCP & 841 & ATG-CAC-TCT-CTC-CTG-GGT-ATG-CGC-AAT-TAA- \\
\hline \multirow[t]{2}{*}{ F10dCP } & 841 & $\begin{array}{l}\text { ATG-CAC-TTT-CTC-CTG-GGT-ATG-CGC-AAT-TAA- } \\
※-※-\end{array}$ \\
\hline & & $\mathrm{C}<>\mathrm{T}$ \\
\hline F8dCP & 281 & $-\mathrm{M}-\mathrm{H}-\mathrm{S}-\mathrm{L}-\mathrm{L}-\mathrm{G}-\mathrm{M}-\mathrm{R}-\mathrm{N}-\mathrm{Stop}$ \\
\hline F9dCP & 281 & $-\mathrm{M}-\mathrm{H}-\mathrm{S}-\mathrm{L}-\mathrm{L}-\mathrm{G}-\mathrm{M}-\mathrm{R}-\mathrm{N}-\mathrm{Stop}$ \\
\hline F10dCP & 281 & $-\mathrm{M}-\mathrm{H}-\mathrm{F}-\mathrm{L}-\mathrm{L}-\mathrm{G}-\mathrm{M}-\mathrm{R}-\mathrm{N}-\mathrm{Stop}$ \\
\hline
\end{tabular}

${ }^{\text {z }}$ Symbol: $※$ indicates missense mutations: $\mathrm{G}<>\mathrm{A}$, or $\mathrm{C}<>\mathrm{T}$. 
In this work, preliminary cluster analysis revealed the biodiversity of the PRSV in Hainan. According to the NJ clustering results, three subgroups of PRSV were found among the Hainan isolates but those were distinct from the isolates from other regions. Le Dong was the major region for papaya planting before PRSV broke out in the 2010s, when the virus almost destroyed the papaya industry in the area. Hence, Le Dong is thought of as the center of the virus infection, and farmers started to move out of this region to other regions such as Wen Chang, Chang Jiang, Cheng Mai, and San Ya. Our phylogeographic analysis further revealed a virus-region preference pattern during the movement: San Ya (Hainan subgroup I), Cheng Mai (subgroup II), and Chang Jiang and Wen Chang (subgroup III). However, there was no clear conclusion about whether the virus-region correspondence related to the planting zone transition. Additionally, we also detected the rare PLDMV virus in Le Dong region. PLDMV was believed to be a minor but more severe virus in Taiwan and also a nontarget virus for most CPGMO papaya, except the double resistance papaya developed by Dr. Yeh in Taiwan (Kung et al. 2009). Close attention needs to be paid to monitoring PLDMV on Hainan Island in future work.

The PCR-based method often proved to be a useful and accurate tool to identify the pathogens. In our work, most of the collected samples with symptoms were confirmed as positive in PCR testing, including three samples further identified as PLDMV. There was only one sample (F15d from Chang Jiang) with recorded symptoms tested as negative with both PRSV- and PLDMV-specific primers. In our work, we counted a sample as positive if any one of three genes (CP, NIb, and $\mathrm{HC}$-Pro) was positive. Only 19 of 61 samples tested positive with all three genes, with the rest of the samples failing to amplify one or two genes. One possible explanation was due to the PCR primers, because most of PCR primers were designed with reference PRSV genomes from Hawaii, Taiwan, and Hainan.

PRSV is distributed worldwide. Until recently, researchers proposed a likely origin in India approximately 2,250 years ago, expansion to Thailand and China approximately 600 years ago, and then reaching America approximately 200 years ago (Olarte Castillo et al. 2011). The author also questioned whether PRSV-W is the true ancestral type because papaya was first introduced to India approximately 400 years ago and PRSV emerged in cucurbits; however, the author also mentions that more sequences are necessary to clarify the claim (Olarte Castillo et al. 2011). Our current work enlarged the PRSV-HN populations (Hainan III group, in this study) and PRSV-HN2 populations (Hainan II). Also we suggested a novel Hainan I group.

In plant viruses, genomic variation caused by mutation makes disease control even more complicated. Our survey revealed the divergence of PRSV in Hainan described above. Among our samples, F8d, F9d, and F10d were collected from the same infected tree but showed slightly different visual symptoms (data not shown), and sequence analysis showed significant differences between those three and the reference isolates HQ424465: 23 neutral mutations and 9 missense mutations (Table 2). Recently, Dr. Yeh and his team reported that CP-transgenic resistance of papaya could be broken down by the suppression of the host defense reaction and Taiwan PRSV "super virus" isolates 5 to 19 have a stronger silencing suppressor HC-Pro than other isolates (Kung et al. 2015). Furthermore, the study suggested that slight modifications by specific site mutation technology in HC-Pro might alter its silencing suppression ability (Kung et al. 2015). Hainan Island shares a similar situation as Taiwan Island (the great diversity of virus) and it would not be surprising if some super virus is found in Hainan (S. D. Yeh, personal communication).

Thus far, there is no clear clue to explain the diversity in Hainan. Commonly, natural evolution, transportation, and mutation were most possible mechanisms. Hawaiian papaya production was mildly affected by PRSV in early 1937, and became more severe around 1950, either due to PRSV mutation or the introduction of a more aggressive isolate (Tripathi et al. 2008). PRSV mutation may also have changed PRSV-P to PRSV-W because the appearance of PRSV-P in Australia was due to mutations in the established PRSV-W that provided the ability to infect papaya (Gonsalves et al. 2010). PRSV are also easily mutated by using a chemical mutagen (e.g., nitrous acid) (Yeh and Gonsalves 1984). Regarding the great diversity of PRSV in Hainan, several possible hypotheses need to be tested in the future, including local native PRSV and their diversity were driven by natural evolution pressure, frequent importation and exchange accelerated and complicated the virus diversity in Hainan, large amounts of chemical pesticide were used to prevent the virus (even through none of those are reported to be mutagens), or sequence-specific CP transgene papaya raised the nontargeted virus development.

The present work has provided many new insights into the diversity of PRSV in Hainan. (i) We confirmed and expanded the two previously published Hainan populations (Hainan II and III). (ii) We also reported a novel PRSV population, Hainan I. (iii) Three Hainan types of PRSV have varied distribution among the cities. (iv) By surveying the diversity of PRSV in Hainan, we verified our previous hypothesis that the higher divergence and distinct differences from other sources of PRSV suggest that transgenic papaya from Taiwan and Hawaii would not be successful in Hainan.

\section{ACKNOWLEDGMENTS}

This work was supported by the International Advanced Agricultural Science and Technology Projects of China Ministry of Agriculture (2013Z15, 2014-Z17, and 2015-Z23) and the Hainan Applied Technology Development and Demonstration Project (ZDXM2014052). We thank S.-D. Yeh (National Chung Hsing University, Taiwan), J. J. Hu (University of Hawaii), and D. Gonsalves (United States Department of Agriculture Pacific Basin Agricultural Research Center) for providing information on virus diversity analysis.

\section{LITERATURE CITED}

Felsenstein, J. 1985. Confidence limits on phylogenies: An approach using the bootstrap. Evolution 39:783-791.

Ferreira, S. A., Pitz, K. Y., Manshardt, R., Zee, F., Fitch, M., and Gonsalves, D. 2002. Virus coat protein transgenic papaya provides practical control of Papaya ringspot virus in Hawaii. Plant Dis. 86:101-105.

Gonsalves, D., Carr, J. B. and Suzuki, J. Y. 2010. Papaya ringspot virus. Online publication. Plant Health Instruct. doi:10.1094/PHI-I-2010-1004-01

Hall, T. A. 1999. BioEdit: A user-friendly biological sequence alignment editor and analysis program for Windows 95/98/NT. Nucleic Acids. Symp. Ser. 41: 95-98.

Kung, Y. J., Bau, H. J., Wu, Y. L., Huang, C. H., Chen, T. M., and Yeh, S. D. 2009. Generation of transgenic papaya with double resistance to Papaya ringspot virus and Papaya leaf-distortion mosaic virus. Phytopathology 99: 1312-20.

Kung, Y. J., You, B. J., Raja, J. A. J., Chen, K. C., Huang, C. H., Bau, H. J., Yang, C. F., Huang, C. H., Chang, C. P., and Yeh, S. D. 2015. Nucleotide sequence-homology-independent breakdown of transgenic resistance by more virulent virus strains and a potential solution. Sci. Rep. 5:Article 9804. doi:10.1038/srep09804

Larkin, M. A., Blackshields, G., Brown, N. P., Chenna, R., McGettigan, P. A., McWilliam, H., Valentin, F., Wallace, I. M., Wilm, A., Lopez, R., Thompson, J. D., Gibson, T. J., and Higgins, D. G. 2007. Clustal W and Clustal X version 2.0. Bioinformatics 23:2947-2948.

Lu, Y. W., Shen, W. T., Zhou, P., Tang, Q. J., Niu, Y. M., Peng, M., and Xiong, Z. 2008. Complete genomic sequence of a Papaya ringspot virus isolate from Hainan Island, China. Arch. Virol. 153:991-993.

Olarte Castillo, X. A., Fermin, G., Tabima, J., Rojas, Y., Tennant, P. F., Fuchs, M., Sierra, R., Bernal, A. J., and Restrepo, S. 2011. Phylogeography and molecular epidemiology of Papaya ringspot virus. Virus Res. 159:132-140.

Purcifull, D. E., and Hiebert, E. 1979. Serological distinction of watermelon mosaic virus isolates. Phytopathology 69:112-116.

Qian, P. G. 2012. PRSV caused eighty percent of papaya yield lost in LeDong City. Pestic. Mark. News 21:43. (In Chinese)

Rao, X. Q., Li, Y. Y., Ruan, X. L., Yan, C., Zhang, S. G., and Li, H. P. 2012. Variation of neomycin phosphotransferase II marker gene in transgenic papaya plants under the field cultivation. Food Biotechnol. 26:293-306. 
Saitou, N., and Nei, M. 1987. The neighbor-joining method: A new method for reconstructing phylogenetic trees. Mol. Biol. Evol. 4:406-425.

Tamura, K., Peterson, D., Peterson, N., Stecher, G., Nei, M., and Kumar, S. 2011. MEGA5: Molecular evolutionary genetics analysis using maximum likelihood, evolutionary distance, and maximum parsimony methods. Mol. Biol. Evol. 28:2731-2739.

Teichmann, S. A., and Mitchison, G. 1999. Is there a phylogenetic signal in prokaryote proteins? J. Mol. Evol. 49:98-107.

Tennant, P. F., Gonsalves, C., Ling, K. S., Fitch, M., Manshardt, R., Slightom, J. L., and Gonsalves, D. 1994. Differential protection against Papaya ringspot virus isolates in coat protein gene transgenic papaya and classically cross-protected papaya. Phytopathology 84:13591366.
Tripathi, S., Suzuki, J. Y., Ferreira, S. A., and Gonsalves, D. 2008. Papaya ringspot virus-P: Characteristics, pathogenicity, sequence variability and control. Mol. Plant Pathol. 9:269-280.

Tuo, D. C. 2011. Page 86 in: PRSV-P Type Hainan Isolates Full-Length cDNA Cloning and Use to Construct Infection Vector. Hainan University, Haikou, Hainan, China. (In Chinese])

Webb, R. E., and Scott, H. A. 1965. Isolation and identification of watermelon on mosaic viruses 1 and 2. Phytopathology 55:895-900.

Yeh, S. D., and Gonsalves, D. 1984. Evaluation of induced mutants of Papaya ringspot virus for control by cross protection. Phytopathology 74:1086-1091.

Yeh, S. D., Jan, F. J., Chiang, C. H., Doong, T. J., Chen, M. C., and Bau, H. J. 1992. Complete nucleotide sequence and genetic organization of papaya ringspot virus RNA. J. Gen. Virol. 73:2531-2541. 